\title{
Compounds extracted from heads of African stingless bees (Hypotrigona species) as a prospective taxonomic tool
}

Ndungu, N. N. ${ }^{1,2^{*}}$, Kiatoko N. ${ }^{1}$, Masiga, D. K. ${ }^{1}$ Raina S. K. ${ }^{1}$, Pirk C. W. W. ${ }^{2}$ and Yusuf A. A. ${ }^{2}$

${ }^{1}$ International Centre of Insect Physiology and Ecology (icipe), P.O. Box 30772-00100, Nairobi, Kenya

${ }^{2}$ Social Insects Research Group, Department of Zoology and Entomology University of Pretoria, Private Bag X20, Hatfield, 0028 Pretoria

*Corresponding author email: nellymucugu@gmail.com

Phone: +254721490071

\section{Acknowledgements}

The authors would like to thank members of Bee Health and Molecular Biology and Bioinformatics (MBBU) teams at ICIPE for their technical support. We acknowledge the financial support for this research by the following organizations and agencies: the European Union (EU) (Grant Contract No. DCI-FOOD/2013/313-659: African Reference Laboratory (with satellite stations) for the Management of Pollination Bee Diseases and Pests for Food Security); the South African National Research Foundation (NRF) Research Career Advancement Fellowship (Grant no: 91419) to AAY; NRF Incentive Funding for Rated Researchers to CWWP and AAY; UK Aid from the UK Government; Swedish International Development Cooperation Agency (Sida); the Swiss Agency for Development and Cooperation (SDC) and the Kenyan Government. The first author was supported by a German Academic Exchange Service (DAAD) In-Region Postgraduate Scholarship. 


\begin{abstract}
Stingless bees are important pollinators of plants, and also producers of honey. Species within the African stingless bee genus Hypotrigona are difficult to differentiate due to morphological similarities. Chemical profiles of whole head extracts from workers of three Hypotrigona species: H. gribodoi, H. araujoi and $H$. ruspolii were studied by gas chromatography-mass spectrometry. A total of 50 components belonging to six chemical classes: hydrocarbons, aldehydes, alcohols, terpenoids, steroids and fatty acids were identified. Twenty nine compounds were found in $H$. araujoi, 26 in $H$. gribodoi and 33 in $H$. ruspolii head extracts. Hydrocarbons, alcohols and fatty acids were the major classes, whilst steroids and terpenoids were minor. Aldehydes were found only in H. ruspolii while terpenoids were only present in extracts of $H$. gribodoi and $H$. araujoi. Eight chemical compounds were specific to $H$. araujoi, six to $H$. gribodoi and nine to $H$. ruspolii, showing both qualitative and quantitative differences. Workers were successfully grouped into their respective species using their chemical profiles. This study shows that head extracts can be used as a reliable taxonomic tool for identifying and differentiating Hypotrigona species.
\end{abstract}

Key words: Speciation, head secretions, Hypotrigona species, chemical profile 


\section{Introduction}

Stingless bees (Apidae; Meliponini) are important pollinators (Kakutani et al. 1993; Heard 1999) with over 500 identified species in 23 genera worldwide (Michener 2007). However, in Kenya, only 12 species of stingless bees belonging to six genera are known to date (Eardley 2004; Nkoba et al. 2012). Stingless bees produce honey with high medicinal value and thus fetch prices twice as much as honey from honey bees (Kiatoko et al. 2016). Stingless bees are reported to have complex communication systems that are regulated by cephalic secretions from both mandibular and labial glands (Engels et al. 1990). These secretions contain pheromones or kairomones that are species-specific (Gracioli-Vitti et al. 2012) inducing either defensive or aggressive behaviour just like in other eusocial insects (Blum and Brand 1972; Le Conte and Hefetz 2008; Yusuf et al. 2015). Secretions from labial glands of stingless bees are known to act as trail pheromones used in recruiting nest mates to food sources (Free 1987; Jarau et al. 2006; Schorkopf et al. 2007). On the other hand, secretions from the mandibular glands have been found to serve as alarm or repellent substances that play a role in interspecific and intraspecific defence, and aggression of the species (Schorkopf et al. 2009). Secretions from the mandibular glands of workers mainly contain hydrocarbons, alcohols, esters, acetones, ketones, carboxylic acids, and aldehydes (Engels et al. 1997; Schorkopf et al. 2009), and these vary with life phases and between castes (Gracioli-Vitti et al. 2012).

Cephalic secretions within species (Lopez et al. 2002) and between closely related species (Francke et al. 2000) show similar chemical profiles. However, those from different species differ as reported from 11 Brazilian social stingless bee species in the genera Tetragonisca and Frieseomelitta (López et al. 2002). Differences in chemical compositions of cephalic extracts between sex and castes (Francke et al. 2000) as well as with age (Engels et al. 1993; Poiani et al. 2014) are attributed to variations in volatile signals which enable workers to discriminate between nest mates and non-nest mates (Francke et al. 2000). 
Chemical compositions of the mandibular as well as those of the cephalic extracts from some species of Neotropical stingless bees like Scaptotrigona postica and Frieseomelitta species have been studied extensively (López et al. 2002; Patricio et al. 2003; Cruz-López et al. 2005). By contrast, little is known on the cephalic secretions from African stingless bees (reviewed in Leonhardt 2017).

Hypotrigona are small stingless bees ( $2 \mathrm{~mm}$ in size) that are morphologically similar, thus making the species difficult to identify and differentiate (Eardley 2004). The genus Hypotrigona consists of four species; H. gribodoi, H. araujoi, H. ruspolii and H. penna of which the latter is only found in West Africa (Eardley 2004). Several studies have attempted to distinguish Hypotrigona species using various approaches. This includes, Moure (1961) who separated $H$. gribodoi and $H$. araujoi based whole body length. It was further confirmed through breeding experiments by Michener (1959) that $H$. araujoi and $H$. gribodoi could not mate and were indeed two separate biological species. In addition, Eardley (2004) used morphologies of the legs, wings, heads and thoraces of workers to describe and differentiate the species. Despite the many attempts to differentiate Hypotrigona species, it still remains difficult to identify these species without the required expert taxonomic knowledge often needed to interpret the various taxonomic keys. Therefore, there is an urgent need to develop other tools which can be used to identify and correctly differentiate Hypotrigona species.

The aims of this study were to first identify and compare the chemical compositions of the extracts from whole heads of the workers of three Hypotrigona species presently identified in Kenya. Secondly, the study documents chemical components of head extracts that can be used to reliably differentiate these species.

\section{Materials and methods}

Bees: Workers of two of the three Hypotrigona species; H. araujoi, and H. ruspolii were collected from queen right colonies in Kakamega forest, Western Kenya whilst workers of $H$. 
gribodoi were collected from Mwingi, Eastern Kenya (Fig. 1). For each species, at least three workers were sampled per colony from three colonies, bringing the total number of samples analysed to 31 .

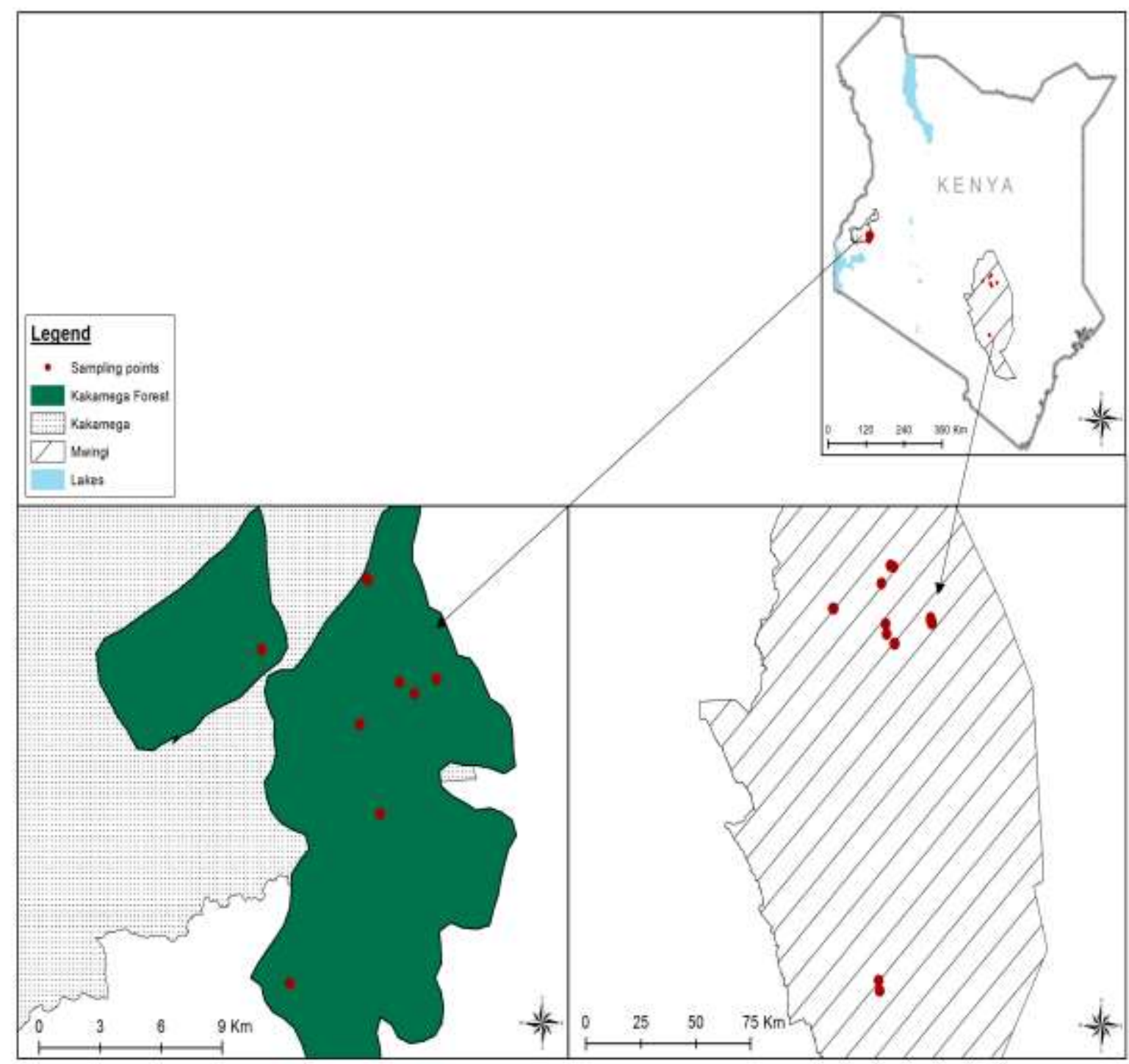

Fig. 1 Map of Kenya showing the two sampling areas, Kakamega forest (green) and Mwingi (chequered box). (modified from Ndungu et al. (2018)

Head extracts: Bees were immobilised on ice, decapitated and their heads were placed into clean pre-labelled $2 \mathrm{ml}$ sample vials containing $200 \mu \mathrm{l}$ of HPLC grade dichloromethane. Samples were then transported to the Department of Zoology and Entomology, University of Pretoria where they were stored at $-20^{\circ} \mathrm{C}$ until required for analysis. For analysis, $100 \mu 1$ of 
each head extract was taken into a $150 \mu \mathrm{l}$ Gas Chromatograph (GC) vial insert and concentrated under a gentle stream of clean nitrogen gas by removing the solvent. Ten $(10) \mu 1$ of GC grade N,O - Bis(trimethylsilyl) trifluoroacetamide (BSTFA) derivatising agent and $10 \mu \mathrm{l}$ of an internal standard mixture (containing $\sim 1 \mathrm{mg}$ of $n$-Heptadecane and $\sim 1 \mathrm{mg}$ Hexadecanoic acid) were added. To ensure complete derivatisation of the analytes, the mixture was allowed to stand for 4 hours in a refrigerator. This derivatisation process was based on the addition of BSTFA which allows the formation of trimethylsilyl (TMS) derivatives of non-volatile compounds like fatty acids, and steroids thus; making them volatile enough to be analysed on a GC. While addition of an internal standard allows for quantification of the individual chemical components relative to the mass ratios (RMR) and peak areas of the internal standards.

Gas chromatographic - mass spectrometric analysis (GC-MS): One microlitre of each derivatised head extract was injected into a Schimadzu QP2010 Ultra GC-MS and analysed in the Electron impact Ionization (EI) mode on an Inert Cap 5MS/NP capillary column (30 $\mathrm{m} \times 0.25 \mathrm{~mm} \times 0.25 \mu \mathrm{m}$; GL Sciences, Tokyo, Japan). The oven was programmed as follows: $120^{\circ} \mathrm{C}$ for $5 \mathrm{~min}$ increased to a final temperature of $300^{\circ} \mathrm{C}$ at $20^{\circ} \mathrm{C} \mathrm{min}^{-1}$ and held for $15 \mathrm{~min}$ bringing the total runtime per sample to 29 minutes. This allows for all the components as well as derivatives to come off the column. Helium was used as the carrier gas at a constant flow rate of $1.0 \mathrm{ml} \mathrm{min}{ }^{-1}$. The ion source was operated at $200^{\circ} \mathrm{C}$ with an interface temperature of $250^{\circ} \mathrm{C}$, and mass spectra were recorded between $40-600 \mathrm{~m} / \mathrm{z}$ at $70 \mathrm{eV}$ with a scan speed of 2500. Compounds were identified based on comparison of mass spectra with those in published mass spectral libraries [NIST11 and Wiley (10th edition)] and an in-house spectral database of derivatised compounds. They were further confirmed using synthetic standards, diagnostic ions and retention indices as applicable (see supplementary material Table S1). 
Chemicals: Authentic synthetic standards for hydrocarbons, tridecanoic, tetradecanoic and pentadecanoic acids (purity $\geq 99 \%$ ) were purchased from Altech Associates Inc. IL, US. Octatriacontanoic acid was purchased from ChemTik, Germany, while all other fatty acids, steroids and terpenoids (purity $\geq 98 \%$ ) were purchased from Sigma-Aldrich GmbH, Germany. Octadecanal was purchased from Albany International and the solvent dichloromethane (HPLC grade Chromsolv®) with a purity of $\geq 99.8 \%$ from Sigma-Aldrich.

Determination of double bond positions in unsaturated hydrocarbons: Position of double bonds in unsaturated hydrocarbons were determined using the dimethyl disulphide (DMDS) technique of Carlson et al. (1989) modified by Fombong et al. (2012). The procedure involves the addition of $100 \mu \mathrm{l}$ DMDS to an aliquot $(100 \mu \mathrm{l})$ of the head extracts followed by the addition of a $10 \mu 130 \mathrm{mg} / \mathrm{ml}$ iodine solution (prepared in diethyl ether) to catalyse the reaction. The mixture was then heated for $12 \mathrm{~h}$ at $50^{\circ} \mathrm{C}$. To neutralise the $\mathrm{I}_{2}, 10 \mu \mathrm{l}$ of $0.5 \mathrm{M}$ aqueous sodium thiosulphate was added to the mixture. The supernatant, containing DMDS adducts was decanted and analysed by GC-MS.

Qualitative and quantitative analysis of chemical profiles: Upon identifying the chemical compounds, the qualitative chemical profiles for each species were established using only those compounds that were present in $>90 \%$ of the samples for that species. These compounds were further grouped into the following chemical classes; hydrocarbons, aldehydes, alcohols, terpenoids, steroids, fatty acids, and unknowns (those compounds that returned no library hits).

Quantitative chemical profiles were established by using the peak area of each component relative to the peak area and relative mass ratio (RMR) of the appropriate internal standard. Concentrations of hydrocarbons, alcohols and terpenoids were computed relative to the RMR of $n$-heptadecane. On the other hand, those of fatty acids, aldehydes and steroids were computed using the RMR of hexadecanoic acid. All concentrations were expressed as 
microgram $(\mu \mathrm{g})$ per bee head. Amounts for each chemical class were used to determine the relative proportions of these components as a percentage of the total concentration.

\section{Statistical Analyses}

Unless otherwise stated, results are presented as means \pm standard errors of means (SEM) of individual chemical components in the total extract per bee head. Differences between chemical classes were tested using Analysis of Variance (ANOVA) and post hoc analysis with Tukey HSD test. Non-metric multidimensional scaling (n-MDS) with Bray-Curtis dissimilarity was used to visualise chemical disparity among the samples coding for both species and colonies. All analyses were carried out using SAS 9.4 (SAS Institute Inc., USA).

\section{Results}

\section{Chemical profiles from head extracts of Hypotrigona species}

A total of 50 compounds were identified, 48 of which belong to six chemical classes. These comprise of hydrocarbons of chain lengths C18 to C34, mainly alkanes and alkenes; monohydric, mono- and polyunsaturated aliphatic alcohols, an aldehyde; saturated and unsaturated ( $\omega-3$ to $\omega-9)$ fatty acids; mono and sesquiterpenes, steroids and two unidentified compounds (Table 1 and Fig. 2).

\section{Qualitative chemical profiles from the head extracts of Hypotrigona species and species specific compounds}

Twenty nine compounds were identified from the head extracts of $H$. araujoi, 26 from $H$. gribodoi and 33 from $H$. ruspolii. Profiles of $H$. araujoi and $H$. gribodoi contained five representative classes of compounds (hydrocarbons, alcohols, fatty acids, steroids, terpenoids as well as unidentified compounds) (Table 1). While those of $H$. ruspolii contained only four classes including an aldehyde with no terpenoids and no unidentified compounds (Table 1).

In terms of percentage proportion for the classes of compounds, profiles of $H$. ruspolii mainly contained hydrocarbons $(43.09 \pm 7.46 \%)$ and alcohols $(29.12 \pm 7.76 \%)$, with small 
proportions of steroids and no terpenoids. Hypotrigona araujoi and $H$. gribodoi head extracts predominantly contained fatty acids $(42.82 \pm 7.27 \%$ and $45.47 \pm 8.35 \%)$; hydrocarbons $(24.50$ $\pm 3.00 \%$ and $27.22 \pm 4.20 \%$ ) and minor proportions of terpenoids. The major chemical compounds found in the three Hypotrigona species, H. araujoi, H. gribodoi and H. ruspolii included; $n$-tricosane, $n$-heptacosane and octadecanoic acid, respectively (Table 1). In addition; pentacosanol, tricosanol and 1-nonacosanol occurred in major proportions in $H$. araujoi, $H$. gribodoi and $H$. ruspolii. Moreover, octadeca-9,12,15-trienoic acid and Z,Z octadeca, 9,12-dienoic acid were present in high proportions in extracts from $H$. araujoi and H. gribodoi respectively (Table 1).

The most abundant compounds in the profiles of $H$. araujoi were octadecanoic acid, $n$ tricosane and octadecanol (Fig. 2). In H. gribodoi: E-octadec-9-enoic acid, Z,Z octadeca, 9,12-dienoic acid, octadecanoic acid and octadecanol. By contrast, profiles of $H$. ruspolii were dominated by $n$-nonacosane, $n$-tricosane and 1-nonacosanol (Fig. 2).

Eight chemical compounds including $n$-octadecane, 1-dotricontanol, heptadecanoic acid, tricosanoic acid, octatriacontanoic acid, desmosterol, farnesol and unidentified compound 2 were specific to $H$. araujoi (Table 1). $n$-Tetratriacontane, tetradecanoic acid, cholest-5-ene, citronellol, isobornel and unidentified compound 1 were specific to $H$. gribodoi. While Z-(9)heptacosene, triacontene, $n$-triacontane, $n$-dotriacontane, octadecanal, hexadecanol, 1eicosanol, 1-octacosanol and 1, 30-triacontanediol (Table 1) were unique to the profile of $H$. ruspolii. 
Table 1 Proportions ( $\% \pm$ SEM) of individual and classes of compounds identified from head extracts of the three Hypotrigona species

\begin{tabular}{|c|c|c|c|c|c|}
\hline ID & $\mathbf{R I}$ & Hydrocarbons & $\begin{array}{l}\text { H. araujoi } \\
(\mathrm{n}=10)\end{array}$ & $\begin{array}{l}\text { H. gribodoi } \\
(\mathbf{n}=12)\end{array}$ & $\begin{array}{l}\text { H. ruspolii } \\
(\mathrm{n}=9)\end{array}$ \\
\hline $\mathrm{H} 1$ & 1800 & $n$-Octadecane* & $0.62 \pm 0.20$ & - & - \\
\hline $\mathrm{H} 2$ & 2000 & $n$-Eicosane & $1.01 \pm 0.11$ & $0.47 \pm 0.10$ & $2.61 \pm 0.30$ \\
\hline $\mathrm{H} 4$ & 2332 & $Z$ (9)-Tricosene & $2.61 \pm 0.57$ & - & $0.85 \pm 0.07$ \\
\hline H5 & 2342 & $n$-Tricosane & $7.10 \pm 0.68$ & $5.37 \pm 0.56$ & $8.32 \pm 1.05$ \\
\hline H6 & 2497 & $n$-Tetracosane & $1.53 \pm 0.20$ & $1.42 \pm 0.23$ & $0.62 \pm 0.07$ \\
\hline H9 & 2845 & $n$-Octacosane & $1.20 \pm 0.20$ & $1.18 \pm 0.20$ & $0.30 \pm 0.08$ \\
\hline $\mathrm{H} 10$ & 2900 & $n$-Nonacosane & $1.77 \pm 0.21$ & - & $15.71 \pm 2.79$ \\
\hline H11 & 2912 & 1,37-Triacontadiene & - & $4.27 \pm 0.42$ & $1.83 \pm 0.22$ \\
\hline H12 & 2996 & Triacontene* & - & - & $3.33 \pm 0.55$ \\
\hline $\mathrm{H} 13$ & 3044 & $n$-Triacontane* & - & - & $3.91 \pm 0.63$ \\
\hline AL1 & 1856 & Octadecanal* $^{*}$ & - & - & $\begin{array}{l}2.63 \pm 0.62 \\
2.63 \pm 0.62\end{array}$ \\
\hline $\begin{array}{l}\text { Alc1 } \\
\text { Alc2 } \\
\text { Alc3 } \\
\text { Alc4 } \\
\text { Alc5 } \\
\text { Alc6 } \\
\text { Alc7 } \\
\text { Alc8 } \\
\text { Alc9 } \\
\text { Alc10 } \\
\text { Alc11 }\end{array}$ & $\begin{array}{l}1794 \\
1961 \\
2253 \\
2507 \\
2575 \\
2694 \\
2762 \\
2800 \\
3074 \\
2798 \\
2998\end{array}$ & $\begin{array}{l}\text { \#Alcohols } \\
\text { Hexadecanol* }^{*} \\
\text { Octadecanol } \\
\text { 1-Eicosanol* } \\
\text { Tricosanol } \\
\text { Tetracosanol } \\
\text { Pentacosanol } \\
\text { 1-Heptacosanol } \\
\text { 1-Octacosanol* } \\
\text { 1-Nonacosanol } \\
\text { 1,30-Triacontanediol* } \\
\text { 1-Dotricontanol* }\end{array}$ & $\begin{array}{l}- \\
0.60 \pm 0.07 \\
- \\
- \\
1.70 \pm 0.20 \\
7.74 \pm 1.27 \\
2.70 \pm 0.26 \\
- \\
- \\
- \\
6.67 \pm 1.20 \\
\mathbf{1 9 . 1 1} \pm \mathbf{3 . 0 0}\end{array}$ & $\begin{array}{l}- \\
- \\
- \\
5.15 \pm 1.03 \\
3.78 \pm 0.27 \\
- \\
- \\
- \\
1.98 \pm 0.32 \\
- \\
- \\
10.91 \pm 1.62\end{array}$ & $\begin{array}{l}2.06 \pm 0.99 \\
0.74 \pm 0.17 \\
0.62 \pm 0.13 \\
4.59 \pm 3.22 \\
0.69 \pm 0.07 \\
1.39 \pm 0.09 \\
2.50 \pm 0.17 \\
1.26 \pm 0.26 \\
11.53 \pm 2.10 \\
3.73 \pm 0.56 \\
- \\
\mathbf{2 9 . 1 2} \pm 7.76\end{array}$ \\
\hline A4 & 2041 & Hexadecenoic acid & $1.38 \pm 0.14$ & $1.33 \pm 0.11$ & $0.96 \pm 0.19$ \\
\hline A5 & 2134 & Heptadecanoic acid* & $0.37 \pm 0.06$ & - & - \\
\hline A6 & 2234 & $\begin{array}{l}\text { Octadeca-9,12,15-trienoic } \\
\text { acid }\end{array}$ & $18.93 \pm 2.62$ & - & $0.51 \pm 0.13$ \\
\hline A7 & 2209 & $\begin{array}{l}Z, Z \text { Octadeca, 9,12-dienoic } \\
\text { acid }\end{array}$ & - & $18.41 \pm 3.32$ & $8.59 \pm 3.90$ \\
\hline A8 & 2215 & $E$-Octadec-9-enoic acid & - & $12.98 \pm 3.70$ & $4.35 \pm 1.38$ \\
\hline A9 & 2207 & Octadecanoic acid & $10.52 \pm 1.35$ & $11.32 \pm 0.87$ & $5.75 \pm 1.90$ \\
\hline A10 & 2542 & Heneicosanoic acid & $1.38 \pm 0.30$ & $0.68 \pm 0.17$ & - \\
\hline A11 & 2732 & Tricosanoic acid* & $0.61 \pm 0.19$ & - & - \\
\hline \multirow[t]{3}{*}{ A12 } & 3808 & Octatriacontanoic acid* & $8.83 \pm 2.48$ & - & \\
\hline & & & $42.82 \pm 7.27$ & $45.47 \pm 8.35$ & $21.19 \pm 7.83$ \\
\hline & & \#Steriods & & & \\
\hline $\mathrm{S} 1$ & 3207 & Desmosterol* & $1.58 \pm 0.19$ & - & - \\
\hline $\mathrm{S} 2$ & 3255 & Cholest-5-ene* & - & $1.68 \pm 0.31$ & - \\
\hline S3 & 3263 & Campesterol & $3.41 \pm 0.33$ & $2.49 \pm 0.28$ & $0.62 \pm 0.18$ \\
\hline S4 & 3354 & Beta Sitosterol & $3.65 \pm 0.47$ & $3.76 \pm 0.57$ & $1.70 \pm 0.60$ \\
\hline \multirow[t]{3}{*}{ S5 } & 3286 & Stigmasterol & $2.69 \pm 0.26$ & $3.39 \pm 0.42$ & $1.66 \pm 0.67$ \\
\hline & & & $11.33 \pm 1.25$ & $11.31 \pm 1.59$ & $3.98 \pm 1.45$ \\
\hline & & \#Terpenoids & & & \\
\hline $\mathrm{T} 1$ & 1312 & Citronellol* & - & $0.58 \pm 0.17$ & - \\
\hline $\mathrm{T} 2$ & 1813 & Farnesol* ${ }^{*}$ & $0.23 \pm 0.07$ & - & - \\
\hline
\end{tabular}

ID = Peak identity on the chromatograph (Fig. 1) based on retention times, RI = Retention index of the compound, \# = TMS derivatives, $*=$ compound present in one species. Bolded and italicised values are mean proportions for each class of 
compound, - = absence/not detected $\mathrm{H}=$ hydrocarbons, $\mathrm{Al}=$ aldehyde, $\mathrm{Alc}=$ alcohols, $\mathrm{A}=$ fatty acids, $\mathrm{S}=$ steroids, $\mathrm{T}=$ terpenoids, $\mathrm{U}=$ unknown compound.
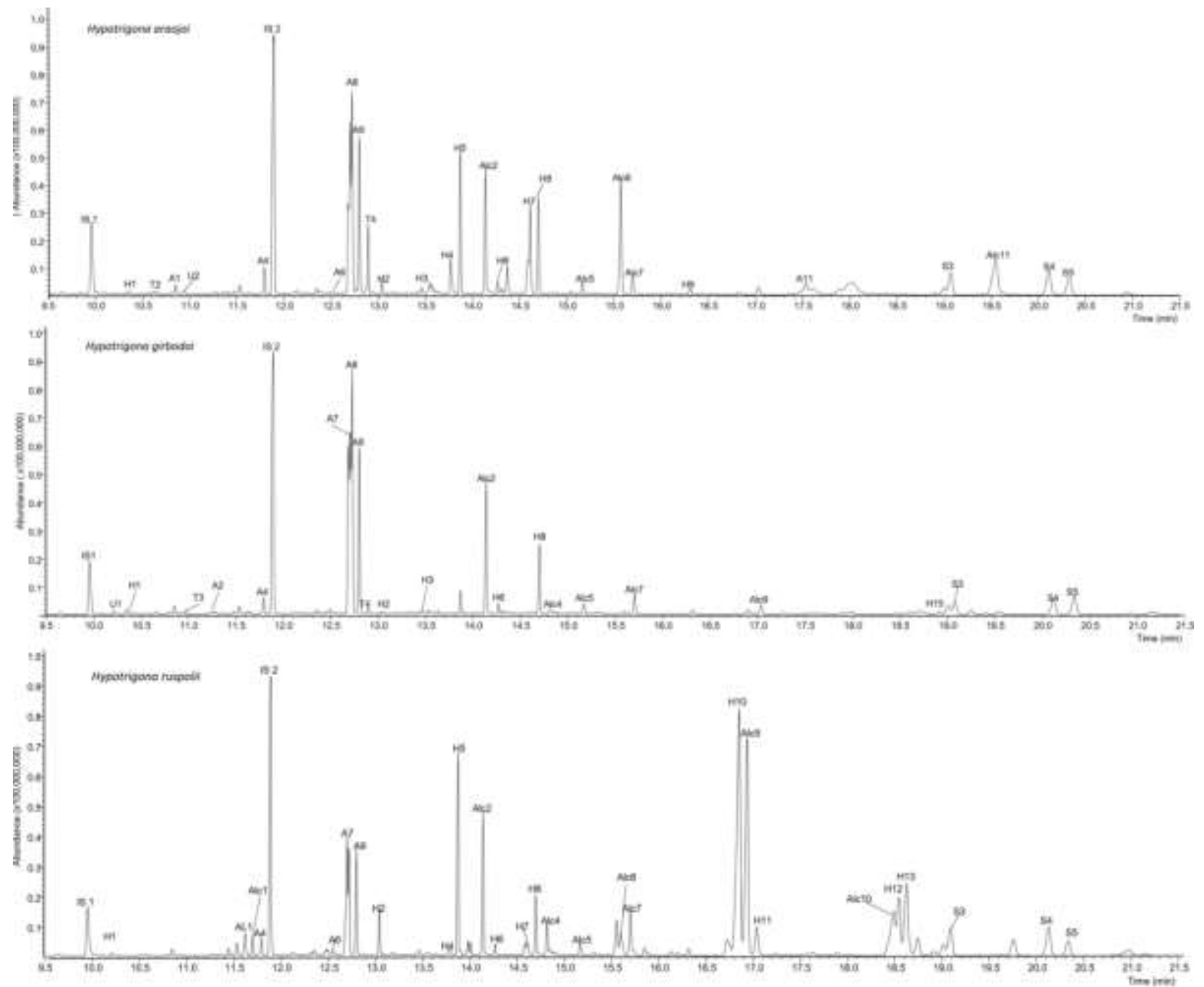

Fig. 2 Representative total ion chromatograms (TICs) of the chemical profiles from head extracts of Hypotrigona araujoi, $H$. girbodoi and H. ruspolii workers respectively. IS1 and IS 2 are the internal standards heptadecane and hexadecanoic acid. Compound were identified by their IDs as listed in Table 1 where A = fatty acids, $\mathrm{AL}=$ aldehyde, $\mathrm{Alc}=$ alcohols, $\mathrm{H}=$ hydrocarbons, $\mathrm{S}=$ steriods, $\mathrm{T}=$ terpeniods and $\mathrm{U}=$ unidentified compounds

\section{Quantitative chemical profiles from head extracts of Hypotrigona species}

Quantitatively, the concentrations ( $\mu \mathrm{g})$ of fatty acids, alcohols, hydrocarbons and steroids varied between the Hypotrigona species. We found significant differences in the concentrations of hydrocarbons, aldehydes, alcohols and steroids from the head extracts in the three Hypotrigona species (ANOVA, Wilks' $\lambda=0.05, \mathrm{~F}(16,22)=4.7744$, df $=18, \mathrm{P}=$ 
0.00045) (Fig. 3). Further, Tukey HSD test shows significant difference in the concentrations of hydrocarbons $(\mathrm{P}=0.00591)$; aldehydes $(\mathrm{P}=0.022)$; alcohols $(\mathrm{P}=0.0263)$ and steroids $(\mathrm{P}=$ 0.0375 ) between $H$. araujoi and $H$. ruspolii. Profiles of $H$. araujoi and $H$. gribodoi had higher amounts of fatty acids $(3.76 \pm 0.62 \mu \mathrm{g}, 2.17 \pm 0.30 \mu \mathrm{g})$ and hydrocarbons $(2.01 \pm 0.23 \mu \mathrm{g}$, $1.36 \pm 0.24 \mu \mathrm{g}$ ) with low amounts of terpenes. On the other hand, H. ruspolii had significant high concentration of alcohols $(5.92 \pm 1.53 \mu \mathrm{g})$ and hydrocarbons $(8.17 \pm 1.85 \mu \mathrm{g})$, whilst steroids and aldehydes were recorded in low amounts (Fig. 3). Using n-MDS with BrayCurtis dissimilarity, workers of the Hypotrigona species were successfully grouped into their respective species (Fig. 4).
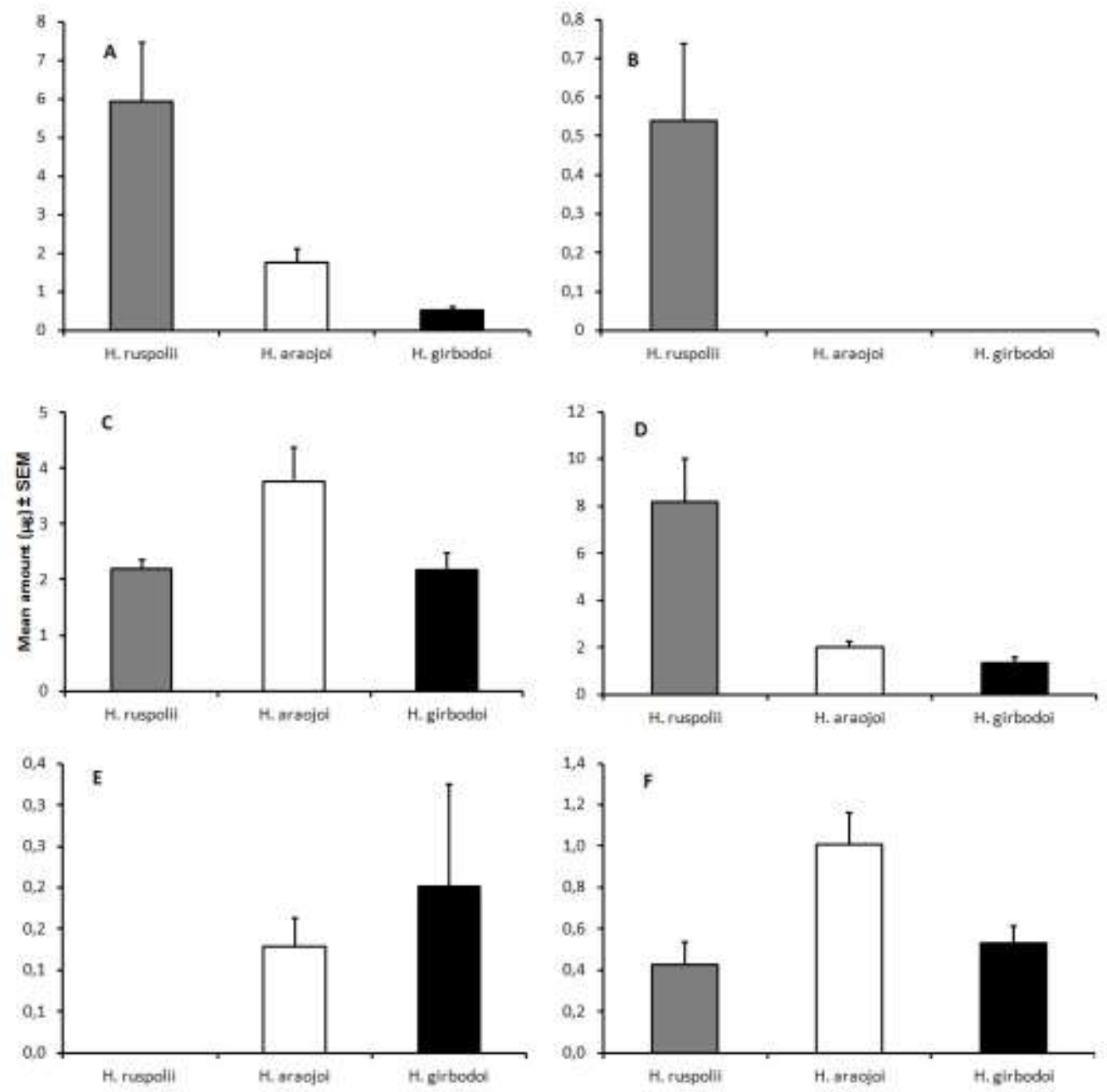

Fig. 3 Concentration $(\mu \mathrm{g})$ (mean \pm SEM) of the classes of compounds identified from head extracts of Hypotrigona ruspolii (grey bars), H. araujoi (open bars) and H. gribodoi (black bars). $\mathrm{A}=$ alcohol, $\mathrm{B}=$ aldehydes, $\mathrm{C}=$ fatty acids, $\mathrm{D}=$ hydrocarbons, $\mathrm{E}=$ terpenoids and $\mathrm{F}=$ steroids. Note the difference in the scale for the $\mathrm{Y}$ axis 


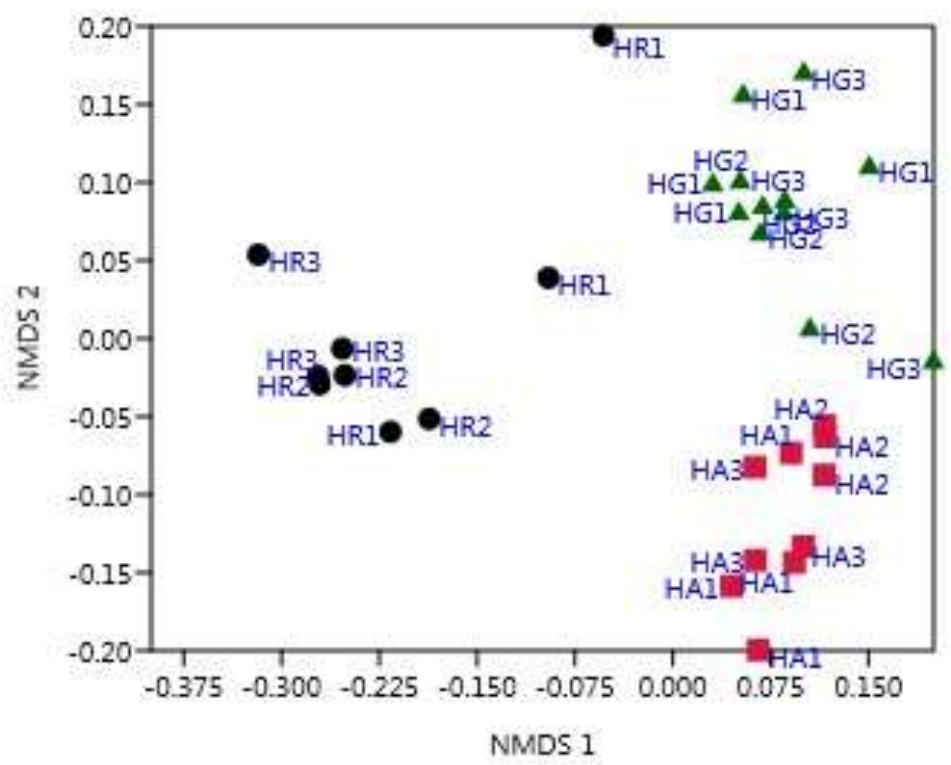

Fig. 4 N-MDS plot of components 1 and 2 showing the separation of $H$ gribodoi, H. araujoi, H. ruspolii into their respective species. The species are represented by the first two alphabets followed by colony numbers. $\mathrm{HR}=H$. ruspolii, $\mathrm{HA}=H$. araujoi and $\mathrm{HG}=H$. gribodoi

\section{Discussion}

We found differences in the chemical profiles of head extracts from the three Hypotrigona species. A total of 50 compounds, 48 from six chemical classes and two unknowns were identified, with the profile of $H$. ruspolii containing 33 compounds, whilst those of $H$. araujoi and $H$. gribodoi, contained 29 and 26 respectively. Extracts from whole heads contain chemical compounds of both surface (cuticular) and glandular origin including those of mandibular and labial glands secretions often used in social insects communication (Free 1987; Leonhardt 2017). Using whole head extracts for chemotaxonomic studies is easier in comparison to glandular dissections since the procedure requires little expertise and can be carried out by amateurs (Meulemeester et al. 2011). Furthermore, volatiles analysed from whole heads and dissected glands (mandibular or labial glands) of stingless bee Frieseomellita species were found to have roughly the same composition of cephalic secretions (López et al. 2002). 
In this study, six classes of compounds; hydrocarbons, alcohols, fatty acids, terpenes, steroids and aldehydes were identified. For the hydrocarbons, alkanes and alkenes were the two major classes found in this study. Alkanes are used for water proofing and their levels could be affected by stages of development i.e. nurse, foragers and guards bees; or changes in temperature and humidity while alkenes have been shown to be involved in communication in the honey bee Apis mellifera (Dani et al. 2005). In addition, cuticular hydrocarbons have been reported to be used for communication by stingless bees (Leonhardt 2017) and a high diversity of alkenes have been reported in neotropical stingless bees (Martin et al. 2017), suggesting divergence in this chemical signature during speciation.

We found that the three Hypotrigona species vary in their alkene profiles, suggesting that these could be used to distinguish the species. Indeed, alkenes and fatty acids have been indicated to be utilised in nest mates recognition (Kather et al. 2011) in stingless bees and also in the termite raiding ant Megaponera analis (Yusuf et al. 2010).

We found high levels of alcohols in all species. Some alcohols such as 1-tetracosanol and tricosanol were common to all species, whilst others were species specific. For instance, 1dotricontanol was specific to $H$. araujoi while hexadecanol, 1-eicosanol, 1-octacosanol and 1,30-triacontanediol were specific to H. ruspolii. The alcohols found in this study differ from those found in neotropical stingless bees. For example, 2-heptanol had been reported mainly in Brazillian stingless bee (Francke et al. 2000) whilst, 2-heptanol, 2-octanol, Z-5tetradecenylbutanoate and Z-7-hexadecenylbutanoate were found in S. postica (Engels et al. 1997). In addition, 2-nonanol and 2-undecanol were detected in Frieseomelitta species (López et al. 2002). In contrast to neotropical stingless bees in which 2-heptanol was found in five of the nine studied stingless bees (Leonhardt 2017), this alcohol was absent in Hypotrigona species, suggesting it could have been acquired after the splitting of the African -Australian and neotropical clade of stingless bees (Rasmussen and Cameron 2010). 
In this study, minor quantities of terpenoids were found in head extracts of $H$. gribodoi and $H$. araujoi while none was detected in $H$. ruspolii. Terpenes are oxygen containing compounds and have been found in the secretions of cephalic glands of some neotropical stingless bees (Francke et al. 2000; Cruz-López et al. 2001; Patricio et al. 2003; Cruz-López et al. 2005). Terpenoids are derived from plant resins which are known to contain terpenes and are used for nest construction and defense (Leonhardt et al. 2009). Here, geranyl linalool was common to two species $H$. gribodoi and $H$. araujoi whilst isoborneol and farnesol were species specific and present only in $H$. gribodoi and $H$. araujoi respectively.

Our study on Hypotrigona shows that chemical components can be effectively used in the taxonomic separation of the three species (see Fig 4) which are currently difficult to tease apart using morphological features.

In conclusion, the composition of the head extracts from the workers of three Hypotrigona species i.e $H$. gribodoi, $H$. ruspolii, $H$. araujoi are different in both quantity and quality. The chemical profiles are species specific and therefore could be utilised in the identification of African Hypotrigona genus up to species levels.

\section{References}

Blum M, Brand J (1972) Social insect pheromones: their chemistry and function. Am Zool 12:553-576.

Carlson, DA, Roan CS, Yost RA et al (1989) Dimethyl disulphide derivatives of long-chain alkenes, alkadienes, and alkatrienes for gas-chromatography mass-spectrometry. Anal Chem 61: 1564-1571.

Cruz-López L, Malo EAE, Morgan ED et al (2005) Mandibular gland secretion of Melipona beecheii: Chemistry and behavior. J Chem Ecol 31:1621-1632. doi: 10.1007/s10886005-5802-3

Cruz-López L, Patricio E, Morgan E (2001) Secretions of stingless bees: the Dufour gland of Nannotrigona testaceicornis. J Chem Ecol 27:69-80.

Dani FR, Jones GR, Corsi S et al (2005) Nest mate recognition cues in the honey Bee: Differential importance of cuticular alkanes and alkenes. Chem Senses 30:477-489. doi: 10.1093/chemse/bji040

Eardley CD (2004) Taxonomic revision of the African stingless bees (Apoidea: Apidae: 
Apinae: Meliponini). Afri Plant Prot 10:63-96.

Engels E, Engels W, Lubke G et al (1993) Age-related patterns of volatile cephalic constituents in queens of the neotropical stingless bee Scaptotrigona-postica Latr (Hymenoptera, Apidae). Apidologie 24:539-548. doi: 10.1051/apido:19930601

Engels W, Engels E, Francke W (1997) Ontogeny of cephalic volatile patterns in queens and mating biology of the neotropical stingless bee, Scaptotrigona postica. Invertebr Reprod \& Dev 31:251-256. doi: 10.1080/07924259.1997.9672583

Engels W, Engels E, Lübke G (1990) Volatile cephalic secretions of drones, queens and workers in relation to reproduction in the stingless bee, Scaptotrigona postica (Hymenoptera: Apidae: Trigonini). Entomol Gen 15:91-101.

Francke W, Lübke G, Schröder W et al (2000) Identification of oxygen containing volatiles in cephalic secretions of workers of Brazilian stingless bees. J Brazil Chem Society 11:562-571.

Fombong AT, Teal PE, Arbogast RT et al (2012) Chemical communication in the honey bee scarab pest Oplostomus haroldi: role of (Z)-9-pentacosene. J Chem Ecol 38: 1463-1473.

Free JBJ (1987) Pheromones of social bees. Chapman and Hall, London. pp154

Gracioli-Vitti LF, Cruz-landim C, Abdalla F (2012) Volatile substances of mandibular gland secretion of a stingless bee: Scaptotrigona postica Latreille. Anim Biol 3:78-88.

Heard TAT (1999) The role of stingless bees in crop pollination. Annu Rev Entomol 44:183206. doi: 10.1146/annurev.ento.44.1.183

Jarau S, Schulz CM, Hrncir M, Francke W, Zucchi R, Barth FG, Ayasse M (2006) Hexyl Decanoate, the first trail pheromone compound identified in a stingless bee, Trigona recursa. J Chem Ecol 32: 1555-1564.

Kakutani T, Inoue T, Tezuka T, Maeta Y (1993) Pollination of strawberry by the stingless bee, Trigona minangkabau and the honey bee, Apis mellifera: an experimental study of fertilization efficiency. Res Popul Ecol 35:95-111.

Kather MR, Drijfhout FP, Martin JS (2011) Task group differences in cuticular lipids in the honey bee Apis mellifera ricarda. J Chem Ecol 37:205-212. doi: 10.1007/s10886-0140423-3

Kiatoko N, Kumar RS, Langevelde F (2016) A vertical compartmented hive design for reducing post-harvest colony losses in three afrotropical stingless bee species (APIDAE: MELIPONINAE). IJDR 6:9026-9034.

Le Conte Y, Hefetz A (2008) Primer pheromones in social hymenoptera. Annu Rev Entomol 53:523-542. doi: 10.1146/annurev.ento.52.110405.091434

Leonhardt S (2017) Chemical ecology of stingless bees. J Chem Ecol 43:385-402. doi: 10.1007/s10886-017-0837-9

Leonhardt SD, Blüthgen N, Schmitt T (2009) Smelling like resin: terpenoids account for species-specific cuticular profiles in South East-Asian stingless bees. Insectes Soc 56:157-170. doi: 10.1007/s00040-009-0007-3 
López LC, Patricio E, Maile R, Morgan E (2002) Secretions of stingless bees: cephalic secretions of two Frieseomelitta species. J Insect Physiol 48:453-458.

Martin SJ, Shemilt, SC, Cândida B et al (2017) Are isomeric alkenes used in species recognition among neo-tropical stingless bees (Melipona spp). J Chem Ecol 43:10661072. doi:10.1007/s10886-017-0901-5

Meulemeester T De, Gerbaux P, Boulvin M (2011) A simplified protocol for bumble bee species identification by cephalic secretion analysis. Insectes Soc 58:227-236. doi: DOI 10.1007/s00040-011-0146-1

Michener C (2007) The Bees of the World, 2nd ed. The Johns Hopkins University Press, Baltimore, Maryland. p803

Michener CD (1959) Sibling species of Trigona from Angola (Hymenoptera, Apinae). Am Mus Novit 1956:1-5.

Moure JS (1961) A preliminary supra-specific classification of the old world meliponine bees (Hymenoptera, Apoidea). Studia Ent 4:181-242.

Ndungu NN, Nkoba K, Sole CL, et al (2018) Resolving taxonomic ambiguity and cryptic speciation of Hypotrigona species through morphometrics and DNA barcoding. J Api Res 8839:1-10. doi: 10.1080/00218839.2018.1426348

Nkoba K, Raina SK, Muli E et al (2012) Species richness and nest dispersion of some tropical meliponine bees (Apidae: Meliponinae) in six habitat types in the Kakamega forest, western Kenya. Int J Trop Insect Sci 32:194-202. doi: 10.1017/S1742758412000355

Patricio E, López L, Maile R, Morgan E (2003) Secretions of stingless bees: the Dufour glands of some Frieseomelitta species (Apidae, Meliponinae). Apidologie 34:359-365. doi: 10.1051/apido:2003027

Poiani SB, Morgan ED, Drijfhout FP, da Cruz-Landim C (2014) Separation of Scaptotrigona postica workers into defined task groups by the chemical profile on their epicuticle wax layer. J Chem Ecol 40:331-340. doi: 10.1007/s10886-014-0423-3

Rasmussen C, Cameron S (2010) Global stingless bee phylogeny supports ancient divergence, variance, and long distance dispersal. Biol J Linn Soc 99:206-232.

Schorkopf D, Hrncir M, Mateus S et al (2009) Mandibular gland secretions of meliponine worker bees: further evidence for their role in interspecific and intraspecific defence and aggression and against their role in food source signalling. J Exp Biol 212:1153-1162. doi: $10.1242 /$ jeb.021113

Schorkopf D, Jarau S, Francke W et al (2007) Spitting out information: Trigona bees deposit saliva to signal resource locations. P R Soc B 274:895-898.

Yusuf AA, Pirk CWW, Crewe RM (2015) Mandibular gland pheromone contents in workers and queens of Apis mellifera adansonii. Apidologie 46:559-572. doi: 10.1007/s13592014-0346-6

Yusuf AA, Pirk CWW, Crewe RM et al (2010) Nestmate recognition and the role of cuticular hydrocarbons in the African termite raiding ant Pachycondyla analis. J Chem Ecol 36:441-448. doi: 10.1007/s10886-010-9774-6 


\section{Supplementary material}

Table S1 Compounds from head extracts of Hypotrigona species and the methods used to identify each by GC-MS.

\begin{tabular}{|c|c|c|c|}
\hline ID & Diagnostic ion & Compound & $\begin{array}{l}\text { Method of } \\
\text { identification }\end{array}$ \\
\hline H1 & 254 & $n$-Octadecane & MS, RI, ST \\
\hline $\mathrm{H} 2$ & 282 & $n$-Eicosane & MS, RI, ST \\
\hline $\mathrm{H} 3$ & 310 & $n$-Docosane & MS, RI, ST \\
\hline $\mathrm{H} 4$ & 322;DMDS:55, 97, 111 & $Z$ (9)-Tricosene & MS, RI, ST \\
\hline H5 & 324 & $n$-Tricosane & MS, RI, ST \\
\hline H6 & 338 & $n$-Tetracosane & MS, RI, ST \\
\hline $\mathrm{H} 7$ & 378;DMDS:173,299,472 & Z-(9)-Heptacosene & MS, RI, ST \\
\hline H8 & 380 & $n$-Heptacosane & MS, RI, ST \\
\hline H9 & 394 & $n$-Octacosane & MS, RI, ST \\
\hline $\mathrm{H} 10$ & 408 & $n$-Nonacosane & MS, RI, ST \\
\hline H11 & 418 & 1,37-Triacontadiene & MS, RI \\
\hline $\mathrm{H} 12$ & 420 & Triacontene & MS, RI \\
\hline H13 & 422 & $n$-Triacontane & MS, RI, ST \\
\hline $\mathrm{H} 14$ & 450 & $n$-Dotriacontane & MS, RI, ST \\
\hline H15 & 478 & $n$-Tetratriacontane & MS, RI \\
\hline$\overline{\mathrm{AL1}}$ & $43,57,69,109,268$ & Octadecanal & MS, RI, ST \\
\hline Alc1 & $43,55,75,103,283,299$ & Hexadecanol & MS, RI, ST \\
\hline Alc2 & $43,75,83,97,103,111,227,269,327$ & Octadecanol & MS, RI, ST \\
\hline Alc3 & $43,57,75,103,111,327,339,355$ & 1-Eicosanol & MS, RI, ST \\
\hline Alc4 & $43,57,75,103,339,381,397$ & Tricosanol & MS, RI \\
\hline Alc5 & $43,57,75,103,111,395,411$ & Tetracosanol & MS, RI \\
\hline Alc6 & $43,57,75,103,111,409,425$ & Pentacosanol & MS, RI \\
\hline Alc7 & $43,57,75,103,111,395,425,437,453$ & 1-Heptacosanol & MS, RI \\
\hline Alc8 & $43,57,75,103,111,395,425,482$ & 1-Octacosanol & MS, RI \\
\hline Alc9 & $43,57,75,103,111,395,425,496$ & 1-Nonacosanol & MS, RI \\
\hline Alc10 & $43,69,82,96,111,124,138,152,292,390,418,454$ & 1,30-Triacontanediol & MS, RI \\
\hline Alc11 & $43,69,82,96,111,125,138,152,294,392,466$ & 1-Dotricontanol & MS, RI \\
\hline A1 & $43,55,73,117,129,145,271,286$ & Tridecanoic acid & MS, RI, ST \\
\hline $\mathrm{A} 2$ & $43,55,73,117,132,145,285,300$ & Tetradecanoic acid & MS, RI, ST \\
\hline A3 & $43,55,73,117,129,145,285,299,314$ & Pentadecanoic acid & MS, RI, ST \\
\hline A4 & $43,55,73,117,132,145,285,269,285,299,313,328$ & Hexadecenoic acid & MS, RI, ST \\
\hline A5 & $43,55,73,117,132,145,201,257,283,299,327,342$ & Heptadecanoic acid & MS, RI, ST \\
\hline A6 & $44,95,121,149,163,177,191,205,263,350$ & $\begin{array}{l}\text { Octadeca-9,12,15-trienoic } \\
\text { acid }\end{array}$ & MS, RI, ST \\
\hline A7 & $41,55,67,73,81,95,109,117,129,262,337,352$ & $\begin{array}{l}Z, Z \text { Octadeca, 9,12-dienoic } \\
\text { acid }\end{array}$ & MS, RI, ST \\
\hline A8 & $41,55,67,73,81,96,110,117,129,145,264,311,339,354$ & E-Octadec-9-enoic acid & MS, RI, ST \\
\hline A9 & $43,55,69,73,117,132,145,201,313,327,341,356$ & Octadecanoic acid & MS, RI, ST \\
\hline A10 & $43,55,73,117,132,145,201,339,355,383,398$ & Heneicosanoic acid & MS, RI, ST \\
\hline A11 & $43,55,73,117,132,145,201,339,355,383,426$ & Tricosanoic acid & MS, RI, ST \\
\hline A12 & $69,83,127,180,222,265,565$ & Octatriacontanoic acid & MS, RI \\
\hline S1 & $\begin{array}{l}41,55,69,73,75,81,95,107,119,129,145,159,253, \\
327,343,351,366,372,441,456\end{array}$ & Desmosterol & MS, RI, ST \\
\hline S2 & $43,73,75,129,441,456,531,547$ & Cholest-5-ene & MS, RI, ST \\
\hline S3 & $41,43,55 / 57,73,129,343,367,382,457,472$ & Campesterol & MS, RI, ST \\
\hline S4 & $41,43,55,73,129,357,381,396,471,486$ & Beta Sitosterol & MS, RI, ST \\
\hline S5 & $\begin{array}{l}41,43,55,69,73,83,129,255,351,355,379,394,469 \text {, } \\
484\end{array}$ & Stigmasterol & MS, RI, ST \\
\hline T1 & $73,81,95,123,143,213,228$ & Citronellol & MS, RI, ST \\
\hline $\mathrm{T} 2$ & $41,69,73,75,93,135,143,156,189,279,294$ & Farnesol & MS, RI, ST \\
\hline $\mathrm{T} 3$ & $75,81,95,117,147,167,191,211,269,284$ & Isoborneol & MS, RI, ST \\
\hline $\mathrm{T} 4$ & $41,69,81,107,136,161,189,221,247,257,290$ & Geranyllinalool & MS, RI, ST \\
\hline U1 & $73,75,103,129,199,217,287$ & Unidentified 1 & \\
\hline $\mathrm{U} 2$ & $73,75,99,103,129,173,259$ & Unidentified 2 & \\
\hline
\end{tabular}

ID $=$ the identity of peaks as represented in Fig. 1, MS = published mass spectra from MS libraries (NIST and Wiley), RI $=$ retention index and $\mathrm{ST}=$ identification confirmed using synthetic standard compound. 